\title{
O APRIMORAMENTO DA TECNOLOGIA E SEU POTENCIAL DE FOMENTAR AVANÇOS E RETROCESSOS SOCIAIS NA SOCIEDADE DA INFORMAÇÃO
}

\author{
Devanildo de Amorim Souza ${ }^{1}$ \\ Cristina Anita Schumann Lereno Terzidis ${ }^{2}$ \\ Ricardo Libel Waldman ${ }^{3}$
}

\begin{abstract}
Resumo
A presente trabalho visa desenvolver entendimentos básicos sobre o que se entende por rede de computadores, ciberespaço, identidade digital, espaço social cibernético e tecer considerações sobre a atualidade tecnológica. Ademais, este trabalho teve como substrato a consulta da literatura científica especializada e livros concernentes ao tema. Com base na análise bibliográfica, avaliou-se a consistência das informações e dos dados apresentados através do método indutivo. Assim, infere-se que a tecnologia pode trazer infindáveis benefícios para a vida em sociedade, mas, fomentá-la de modo açodado, pode contribuir para o fortalecimento de um modelo dominante de pensamento.
\end{abstract}

Palavras-chave: Artificial; Cibercultura; Diversidade; Inteligência; e Simbólica.

\section{THE IMPROVEMENT OF TECHNOLOGY AND ITS POTENTIAL TO PROMOTE SOCIAL ADVANCES AND RETRACTIONS IN THE INFORMATION SOCIETY}

\section{Abstract/Resumen/Résumé}

The present work aims to develop basic understandings about what is meant by computer network, cyberspace, digital identity, cyber social space and to make considerations about the current technology. In addition, this work had as a substrate the consultation of specialized scientific literature and books concerning the theme. Based on the bibliographic analysis, the consistency of the information and data presented through the inductive method was evaluated. Thus, it is inferred that technology can bring endless benefits to life in society, but, fostering it in a timely manner, can contribute to the strengthening of a dominant model of thought.

Keywords: Artificial; Cyberculture; Diversity; Intelligence; and Symbolic.

\footnotetext{
${ }^{1}$ Mestrando em Direito pelo Centro Universitário das Faculdades Metropolitanas Unidas - FMU/SP. Graduado em Direito - FMU/SP. Bolsista CAPES. Curriculum Lattes: http://lattes.cnpq.br/3461110540185889. ORCID: https://orcid.org/0000-0003-2489-1373. E-mail: devanildosouza@ outlook.com.br. São Paulo/SP, Brasil.

${ }^{2}$ Mestranda em Direito pelo Centro Universitário das Faculdades Metropolitanas Unidas - FMU/SP. Graduada em Direito da Faculdades Metropolitanas Unidas. Advogada. Lattes: http://lattes.cnpq.br/8686665865896351 Email: terzidisadv@outlook.com. São Paulo/SP, Brasil.

${ }^{3}$ Doutor em Direito pela UFRGS. Coordenador e professor do Mestrado em Direito - FMU/SP e Professor da Escola de Direito da PUC-RS. Lattes: http://lattes.cnpq.br/5138875442525636. E-mail: ricardo.waldman@fmu.br. São Paulo/SP, Brasil.
} 


\section{INTRODUÇÃO}

Hodiernamente se noticia o movimento da virtualização da informação, da comunicação e dos corpos que, por sua vez, denomina-se ciberespaço ou sociedade da informação.

Ocorre que o aprimoramento da tecnologia, se por um lado fomenta ganhos exponenciais - como predições de catástrofes ou direcionamentos de políticas públicas -, por outro lado passou a representar aumento dos mecanismos de controle do espaço digital e, por conseguinte, impacta os modelos sociais de vida em sociedade. Destarte, a comunidade cientifica evidencia que tais mecanismos estão sendo robustecidos e lapidados para atender demandas privadas e governamentais.

Incialmente se faz importante mencionar que ciberespaço se distingue de sociedade da informação, pois essa é compreendida como uma sociedade e uma economia que faz das tecnologias da informação a base dos processos econômicos e sociais.

De outro modo, sociedade da informação é o momento histórico econômico-social em que a entidade intangível é o objeto do processo comunicacional (OLIVEIRA; WALDMAN, 2020, p. 258).

À vista disso, tendo por base esse processo de centralização de poder informacional capitaneado pelos principais agentes desenvolvedores desse modelo, é sabido que as formas de dominação sempre estiveram presentes em todos os momentos da história do ser humano, seja pela preponderância do capital econômico, seja pelo uso da força física - ou mais modernamente, a bélica -, seja pelo uso de vertente ideológicas dominante.

Sabendo que soberania significa a capacidade de definir quem é importante e quem não é, quem é descartável e quem não é -, a história aponta que a força física (bélica) fora largamente utilizada como mecanismo de "barganha" para legitimar ou impor ponto de vista dominante.

Por outro lado, com o aprimoramento do pensamento humano, visando-se impor a vontade do dominante de forma mais sutil e barata, a força imaterial das ideologias (vertentes ideológicas) tornou-se a mais sofisticada técnica de dominação em massa da humanidade.

Entre idas e vindas, há momentos históricos que o ser humano tende por esta ou por aquela forma ideológica de pensamento para fixar e legitimar suas tomadas de decisões e, 
portanto, "escolher" qual vida viver - vindo a optar pelo modelo de vida tido por mais adequado para se viver.

Porém, como consequência necessária, quando se escolher qual é o modelo adequado, automaticamente se diz qual não é. Ou seja, elege-se uma forma de mundo em detrimento de todas as outras formas possíveis.

Visando compreender essa problemática, o presente estudo teve como substrato a consulta da literatura científica especializada e livros concernentes ao tema e, com base na análise bibliográfica, avaliou-se a consistência das informações e dos dados apresentados através do método dedutivo, partindo de premissas gerais sobre a internet demais tecnologias da informação para análise dos riscos gerados por ela.

À vista disso, com base nos materiais bibliográficos e método proposto, visou-se inferir possíveis pontos concernentes ao aprimoramento da tecnologia e seu potencial de fomentar avanços e retrocessos sociais na sociedade da informação.

Com o intuito de alcançar o objetivo proposto, incialmente o presente trabalho aborda o conceito de rede de computadores e relata alguns marcos históricos que contribuíram para aquilo que se compreende hodiernamente por rede de computadores.

Nessa linha, como consequência lógica, o presente estudo apresenta o conceito de ciberespaço e de identidade digital os diferenciando e apontando efeitos positivos e negativos até se chegar na ideia de espaço social cibernético que, por sua vez, apresenta-se como consequência dos anteriores.

Por fim, se chega as benécias e malefícios da atualidade tecnológica, pois o aprimoramento da tecnologia pode ser relevante para a monopolização de poder bem como para descentralização dele.

\section{1 - REDE DE COMPUTADORES}

Inicialmente, compreender a origem do sistema mundial de computadores revela-se importante, pois, desde seu nascedouro já se identifica o interesse dos Estados na sua implantação.

Outrossim, se faz importante ressaltar que a história da Internet possuí por nascedouro a formação da Rede da Agência de Projetos de Pesquisa Avançados (ARPANET) no final de 1960 que, por sua vez, surgiu de um projeto do Departamento de Defesa norte- 
americano que, com o objetivo de superar a tecnologia soviética, veio a mobilizar recursos de pesquisa, particularmente do mundo universitário, para desenvolver uma rede interativa de computadores (CASTELLS, 2003. p. 16).

Assim, o objetivo seguinte foi buscar meios de fazer possível a conexão da ARPANET com outras redes de computadores, a começar pelas redes de comunicação que a ARPA estava administrando, a PRNET e a SATNET (CASTELLS, 2003. pp. 16-17).

Daí por diante a ideia de rede de computadores tornou-se possível, mas foram Cerf, Postel e Crocker em 1978 os responsáveis por dividir o TCP em duas partes, acrescentando um protocolo intrarrede (IP), o que gerou o protocolo TCP/IP -, padrão segundo o qual a Internet continua operando até hoje (CASTELLS, 2003. p. 17).

Com efeito, conforme mencionado supra, a Internet nasceu da improvável interseção da big science da pesquisa militar e da cultura libertária (CASTELLS, 2003. p. 23).

Assim, dispondo de uma arquitetura de protocolos abertos, desde seu nascimento, a rede permite que os usuários participassem do aperfeiçoamento de softwares para a Internet.

Destarte, com o aprimoramento da ideia de rede de computadores, na atualidade esta pode ser compreendida como o "Conjunto de computadores autônomos interconectados por uma única tecnologia" (TANENBAUM, 2003, p. 18).

\section{2 - CIBERESPAÇO}

Com o advento e aprimoramento das tecnologias, o virtual fora impulsionado e veio a fazer parte do cotidiano das pessoas fazendo desse espaço uma espécie de ambiente virtual coletivo, dinâmico e "monitorável".

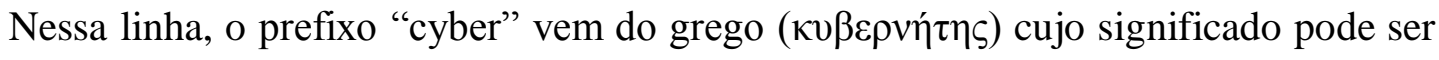
compreendido como a "arte de governar", "aquele que governa" ou "controle" (KELLNER, 2001, pp. 377-419).

Nesse sentido, o físico Norbert Wiener cunhou, nos anos 40, o termo cibernética com o significado de ciência do controle e da comunicação entre os seres vivos e as máquinas (MONTEIRO, 2007, p.1).

Desde então o prefixo "ciber" passou a referenciar diversos termos relacionados ao domínio da computação e das "máquinas inteligentes" (CASCAIS, 2001 apud MONTEIRO, 2007, p. 1). 
Já o termo ciberespaço foi empregado pela primeira vez pelo norte-americano Willian Gibson em um conto (Burning Chrome) em 1982 (MONTEIRO, 2007, p.3).

Porém, comumente encontramos na Literatura que o termo ciberespaço foi cunhado por Gibson em sua obra Neuromancer publicada no ano de 1984 (LÉVY, 1999, p. 92).

Para Gibson, na obra supramencionada, o ciberespaço é:

\begin{abstract}
Uma alucinação consensual vivida diariamente por bilhões de operadores autorizados, em todas as nações, por crianças aprendendo altos conceitos matemáticos... Uma representação gráfica de dados abstraídos dos bancos de dados de todos os computadores do sistema humano. Uma complexidade impensável. Linhas de luz abrangendo o não-espaço da mente; nebulosas e constelações infindáveis de dados. Como marés de luzes da cidade. (GIBSON, 2003, p. 57).
\end{abstract}

Destarte, na atualidade o espaço/tempo virtual proposto por Gibson tornou-se uma realidade inexorável e incontornável, pois passou a permitir a comunicação interpessoal em ambientes virtuais fundido o virtual com o real. Além disso, o ciberespaço adquire uma significação cultural de dimensão global e tornou-se compartilhado por milhões de pessoas de todo o planeta (MONTEIRO, 2007, p.1).

Com efeito, ciberespaço pode ser compreendido como "o espaço de comunicação aberto pela interconexão mundial dos computadores e das memórias dos computadores" (LÉVY, 1999, p. 92).

Ademais, Lévy (1999, p. 92) esclarece na obra que a definição supra inclui o conjunto dos sistemas de comunicação eletrônicos, na medida em que transmitem informações provenientes de fontes digitais ou destinadas à digitalização.

A dualidade virtual e real confronta-se a ponto de haver na literatura quem entenda que o virtual não existe, pois o que de fato existe é o real, já que o ciberespaço é físico, assim como seus componentes (KOEPSELL, 2004, p. 125 apud MONTEIRO, 2007, p.5).

Tal linha de pensamento, pelo menos para o ponto de vista nietzschiano, demonstrase altamente pertinente, pois o virtual não está fora do mundo da vida, mas - sim -, nele. Portanto, o virtual é tão real como o próprio real, pois o que há de fato é a unidade do tempo sem a unidade de espaço.

\title{
3 - IDENTIDADE DIGITAL
}


O evoluir do ciberespaço possibilitou a criação da identidade digital, pois, graças à interação dos usuários, se fez possível desenvolver mecanismo para cooptar informações sobre hábitos, gostos, interesses e tendencias ideológicas.

Diante disso, Marco Antonio Sousa Alves e Marcio Rimet Nobre aludem que:

\begin{abstract}
Não há nenhuma ação ou movimento do indivíduo no ciberespaço que não sirva a alguma finalidade. Quanto maior o rastreamento, análise e processamento dos dados, mais eles servirão como indicadores (de consumo e comportamento). Quanto mais rápida e imediatamente tais dados forem levantados, maior será sua utilidade. Daí a urgência que as mídias digitais colocam para seus usuários, igualmente um sequestro do tempo dos indivíduos (ALVES; NOBRE, 2020, p. 75).
\end{abstract}

À vista disso, identidade digital consiste no resultado das práticas que os indivíduos vêm desenvolvendo online (WILLIAMS et al, 2010 apud COSTA; TORRES, 2011, p. 49). De outro modo, identidade digital é desenvolvida organicamente pelo uso do usuário à medida que informações sobre o usuário se acumulam e desenha um perfil categórico do usuário.

Portanto, sabendo que a web vem moldando a forma como acessamos e produzimos informações, um olhar inicial sobre a identidade digital se dá pelo fato de os usuários mostrarem sua prática online denunciando suas afinidades e descontentamentos em um espaço compartilhado e possivelmente monitorado por entes públicos e privados com interesses que nem sempre são claros quanto a seus objetivos e interesses.

Além do mais, não raras vezes, os detentores das informações possuem interesses opostos aos de seus usuários.

Ademais, a forma que os outros pensam sobre aquele usuário exposto online pode impactar na reputação deste independentemente de ter uma presença online robusta e socialmente vinculada (COSTA; TORRES, 2011, p. 49).

Logo, é interessante notar que quase todos os projetos e atividades que se baseiam no uso de ferramentas e aplicativos da web são, na verdade, formas de criar nossas identidades digitais, mesmo que esse não seja o seu objetivo principal.

Com efeito, na atualidade a identidade digital do usuário está sendo calibrada diuturnamente pelo fato de este sempre estar navegando (ou naufragando) na internet.

Por outro lado, ratificando o impacto da atividade digital no cotidiano das pessoas tanto no campo presencial quanto online, o gerenciamento da identidade digital, se por um lado pode ser utilizado para fins meramente econômicos ou de controle, há um movimento 
internacional de governos e organizações estudando o potencial transformador da tecnologia e seu impacto na sociedade devido as aplicabilidades desta para a promoção de políticas públicas, democratização social e interiorização destas medidas.

\section{4 - ESPAÇO SOCIAL CIBERNÉTICO}

Com a aperfeiçoamento das tecnologias, a imediatez se estendeu ao campo da ação e da retroação à medida da rede informático-mediática (LÉVY, 1993, p. 127). Deste modo, a virtualização veio a promover a unidade do tempo sem a unidade de espaço.

Destarte, pode ser compreendido por Ciberespaço o ambiente que nos permite inúmeras possibilidades de mundo "real", já que este é um universo virtual/real, plástico, fluído e carregado de devires (MONTEIRO, 2007, p. 1).

De tal maneira, a emergência de um novo paradigma tecnológico organizado em torno de novas tecnologias da informação, mais flexíveis e poderosas, possibilita que a própria informação se torne o produto do processo produtivo (CASTELLS, 2016, p. 135) vindo o corpo social que compõe o ciberespaço, a exemplo da indústria automobilística, a impulsionar o ciberespaço e fazer dele um movimento social, global e descentralizado, porém, convergente a um fim, pois, conforme já visto, a rede nasceu da cooperação e, por conseguinte, a rede depende da cooperação dos agentes para se manter operante.

Com efeito, a rede necessita de usuários para se caracterizar como rede e os usurários necessitam da rede para que esta possa interconectá-los e, por conseguinte, é dessa pluralidade de individuais que surge o corpo coletivo devido a esse cooperativismo, pois, mesmo que todos tenham objetivos individuais, necessariamente a busca por esse objetivo o coloca em rede.

Destarte, no que pese cada usurário possuir objetivos particulares, o ciberespaço é exatamente esse mundo particular de cada usuário somado a outros tantos mundos individuais. Assim, o ciberespaço é o resultado desse plural de individuais que resulta nesse corpo coletivo que empresas públicas e privadas são detentoras de centenas de dados de incontáveis pessoas (HARARI, 2018, p. 108).

Assim, surgem soluções e problemas como é o caso da venda de informações sobre consumidores para agregar valor às práticas de publicidade (BIONI, 2019, p. 19). 
Não obstante, o uso de dados sensíveis é outro problema que, na atualidade, devido a interesses conflitantes, cabe à sociedade regular a forma de uso dessas informações para evitar medidas desarrazoadas por partes dos agentes econômicos.

Ademais, no que tange aos dados pessoais sensíveis, a Lei $\mathrm{N}^{\circ} 13.709$, de 14 de agosto de 2018 (Lei Geral de Proteção de Dados Pessoais - LGPD), o conceitua no artigo $5^{\circ}$, II, como aquele "dado sobre origem racial ou étnica, convicção religiosa, opinião política, filiação a sindicato ou a organização de caráter religioso, filosófico ou político, dado referente à saúde ou à vida sexual, dado genético ou biométrico, quando vinculado a uma pessoa natural".

À vista disso, infere-se que a própria seleção de quais seriam estes dados considerados sensíveis apenas ressalta a ideia de que a circulação de determinadas espécies de informação apresentaria um elevado potencial lesivo aos seus titulares, em uma determinada configuração social (DONEDA, 2019, p. 143).

Portanto, é sabido que há uma nova cultura em andamento, que pode ser denominada de "tecnocultura" ou cibercultura, tão abrangente nos seus significados e símbolos, capaz de integrar diferentes campos do conhecimento, das artes, da música e da política (VIEIRA, 2006, p. 2).

\section{5 - A ATUALIDADE TECNOLÓGICA}

A tecnologia, no estágio atual, ora encanta com a sua capacidade de facilitar a vida do homem em sociedade, mas, por vezes, espanta quando verificamos o potencial destrutivo que esta representa para o ser humano. Mas, claro, o problema não é a tecnologia em si, mas, sim, o que os humanos decidem fazer com ela, pois a mesma tecnologia que pode salvar milhares de vidas, também, em mãos erradas, com um simples apertar de um botão, pode servir para ceifá-las.

A título de exemplo, pertinente as benécias do conhecimento tecnológico, a tecnologia blockchain permite um elevado nível de transparência nas transações financeiras e comerciais possibilitando a redução de riscos e custos dos negócios (СТАТОВСКИЙ, 2017, p. 3).

Ademais, a natureza distribuída dos dados inseridos na blockchain propiciam que serviços universais, como prontuário eletrônico, sejam disponibilizados de maneira segura, 
transparente e de fácil acesso pelos atores que participam do processo (SCHAUB, 2018, p. 20).

Com efeito, na República Federativa do Brasil, instituições vinculadas ao Sistema Financeiro Nacional e ao governo brasileiro, como é o caso da Receita Federal do Brasil, já fazem uso dessa tecnologia para prevenção à lavagem de dinheiro e à evasão fiscal (BRASIL, 2020).

Nessa linha, a Agência Nacional de Aviação Civil brasileira (ANAC) veio a utilizar esse modelo de tecnologia em seus ambientes computacionais para prover serviços.

No mesmo sentido, o Ministério da Economia brasileiro aprovou orçamento para o ano de 2020 visando instigar o uso das tecnologias de blockchain para aumento da eficiência da gestão pública e para o processo de arrecadação pública.

Ainda nessa linha, o governo brasileiro, visando estimular a transparência das atividades públicas e estimular a possibilidade interação direta com o cidadão, vem fomentando diversas políticas de inclusão digital que possui como efeito positivo a prestação dos serviços digitais e aumento do controle social sob a administração pública. De tal modo, o cidadão passa a ter maior poder de fiscalização e acesso a mecanismos de denúncia etc.

Além disso, no Brasil e no mundo, o aprimoramento tecnológico possibilita que os governos implantem identidades digitais para seus cidadãos visando que estas informações possam ser facilmente acessadas pelos citadinos e pelas autoridades.

Por outro lado, com o aprimoramento da tecnologia, surgem novas estratégias de guerra que ameaçam a soberania dos Estados e a própria dignidade humana.

A China, por exemplo, visou estipular métricas para quantificar: valor da virtude; índice de produtividade no local de trabalho; dados relacionados à saúde; dados de consumo; relacionamentos interpessoais; atividades políticas; e histórico de geolocalização daqueles que estão expostos ao poder de fiscalização chinesa (WONG; DOBSON, 2019, pp. 220-232).

No Brasil, em fase inicial da pandemia da COVID 19, cogitou-se restringir a liberdade de locomoção dos citadinos fazendo uso de dados de geolocalização. De outro modo, já naquele momento fora divulgado que os dados já estavam disponíveis, ou seja, se quer o cidadão que teve suas informações coletadas tinha conhecimento dos rumos que aquelas informações sensíveis iriam tomar, mas a repercussão negativa foi tamanha que tal medida, pelo menos midiaticamente, recuou. 
Á vista disso, demonstra-se razoável defender que as plataformas e aplicativos de mídia social se tornaram relevantes ferramentas para a governança e centralização de informações em muitos estados-nação (WONG; DOBSON, 2019, pp. 220-232).

Além do mais, de forma indiscutível, podemos afirmar que as plataformas e aplicativos de mídia social podem influenciar, inclusive, em escolha de representantes da nação (BARRETO JUNIOR; VENTURINI JUNIOR, 2020, p. 05).

Nessa linha, a China começou a aplicar um sistema de recompensa e punição que bonifica positivamente aqueles que seguem os ideais do governo chinês e pune aqueles que se desviam delas (WONG; DOBSON, 2019, pp. 220-232).

Com efeito, com o intuito de monopolizar o uso da violência, várias outras tecnologias são mobilizadas para esse fim. A exemplo, sensores a bordo de veículos aéreos não tripulados (VANTs), jatos de reconhecimento aéreo, aviões Hawkeye de alerta precoce, helicópteros de assalto e satélite de observação da Terra. Isso implica dizer que hodiernamente ampliou-se o poder destrutivo da vida humana.

$\mathrm{Na}$ atualidade, um simples apertar de um botão em um continente pode ser determinante para o viver ou para o não viver de algumas centenas de pessoas que possam estar geograficamente a milhares de quilômetros de seu algoz.

Com o emprego da tecnologia bélica militar, aliada a capacidade de garimpagem informacional dos entes públicos e privados, pela primeira vez na humanidade, vislumbra-se uma forma possivelmente onipresente de impor o medo ou a coerção de forma mássica - de maneira razoavelmente barata e com baixa necessidade de demanda de pessoal -, pois o assassinato ou o poder de oprimir por outros meios se tornou precisamente direcionado, asséptico, higienizado e indolor (MBEMBÉ, 2003, p. 29) já que se quer há a necessidade de a vítima ver ou saber quem é seu algoz.

Assim, no modelo atual de sociedade, se quer há a necessidade de se convencer milhares de pessoas as bombardeando com publicidade para fazer as crer que a "verdade" da força dominante de ocasião é a "verdade" mais legitima entre tantas outras possíveis e igualmente legitimas.

Assim, como ocorrera com a Alemanha nazista e em tantos outros regimes autoritários, não se faz tão necessário que ocorra um convencimento massivo para se fomentar a banalização do mal. 
Em tese, no estado atual da técnica, já se vislumbra a possibilidade de existir uma potência, estatal ou não estatal, com capacidade técnica de dominar sem resistência graças a concentração do poder de vigilância e opressão da força dominante de ocasião.

Entende-se por força dominante de ocasião o modelo de coerção e de repressão social que permite o dominante exercer, por meio do Estado, poder sobre toda a sociedade, fazendo-a submeter-se às regras políticas (CHAUí, 1984, p. 83).

Se outrora o uso da força física viabilizava o exercício de poder, hodiernamente a ideologia é um dos meios usados pelos dominantes para exercer a dominação, fazendo com que esta não seja percebida como tal pelos dominados (CHAUÍ, 1984, p. 79).

Além do mais, a revolução tecnológica "prejudicou as capacidades do inimigo", pois suprimiu dele a possibilidade de resistência por viabilizar um modelo de opressão tendente a onipresença, menos custoso do que as sangrentas guerras de combate corpo-a-corpo e com menor intervenção dos agentes que compõe o corpo social nas tomadas de decisão que instrumentalizam o mecanismo de dominação formado por um seleto grupo de agentes com real poder de mando. Outrossim, a revolução tecnológica militar multiplicou, de forma sem precedentes -, a capacidade de destruição dos tidos por inimigos (MBEMBÉ, 2003, p. 30).

Importante salientar que o termo "inimigo" deve ser visto com cautela, pois a história da humanidade é rica em apontar os inimigos de ocasião que sagraram nas mãos da força dominante de ocasião.

Com efeito, uma força tendente a tirania impulsionada pela detenção de poder inquestionável fora por diversas vezes capaz de oprimir grupos étnicos, minorias e até mesmo maiorias - seja com o uso da força física ou, como costumeiramente se vê na atualidade, com o emprego da linguagem por meio da força imaterial das ideologias (CHAUÍ, 1984, p. 79).

Nessa ceda, com o intuito de segregação e/ou de domínio, somente em 2019, o acesso à internet foi inteiramente restrito na Etiópia, Bangladesh, Egito, Índia, Indonésia, Irã, Iraque, Sudão e Zimbábue e parcialmente restrito em outros países (KLIMKE, 2020, p. 1).

Nota-se que a tecnologia proporciona um distanciamento entre a vítima e seu algoz, assim, seguindo a ideia da obra "crime e castigo" do Dostoiévski (1866), quando não há uma divisão letal do trabalho, se faz estabelecer uma empatia entre o algoz e a vítima (patus conjunto) - compaixão diante do outro (VASSOLER, 2018)

No mesmo sentido, Dostoiévski, na obra Crime e castigo, publicada em 1866, descreve o assassínio cometido pelo personagem Raskólnikov. O referido personagem, por 
inferir que a personagem "a velha" não estava à altura do seu objetivo e que ela era desonesta a equipara a um "piolho" e vislumbra a insignificância outro para legitimar seu assassínio (DOSTOIÉVSKI, 2009, p. 80).

Por outro lado, enquanto na obra "Crime e Castigo" Raskólnikov concebe e executa o assassínio, na obra “Os Irmãos Karamázov" vem à tona a ideia da fragmentação da responsabilidade pelo resultado derradeiro. Na referida obra há a figura do mentor do crime protagonizada pelo Ivan Fiodorovitch Karamazov (mentor do parricídio) - e a figura do executor do delito - protagonizado pelo filho bastardo - Smierdiakóv - (executor do parricídio) (DOSTOIÉVSKI, 2012, p. 924).

Contudo, infere-se que quando há uma divisão letal do trabalho, conforme denunciado por Dostoiévski na obra Os Irmãos Karamázov, se verifica que o distanciamento do ser humano de seus pares fomenta tomadas de decisões descoladas de valores éticos e morais, ou seja, usando o sentido clássico do termo, estimula-se valores niilistas (VASSOLER, 2018), ou seja nega-se os princípios e valores tradicionalmente consagrados, sejam eles religiosos, morais, políticos ou sociais.

Nessa linha, conforme relatara Stálin "Uma única morte é uma tragédia; um milhão de mortes é uma estatística", justamente pela ausência de empatia, (patus conjunto) compaixão diante do outro.

Assim, tal descolamento ético se revela possível pelo seguinte:

Muitas vezes o niilista contumaz está à altura do seu relativismo - de sua ruptura ética - no momento do ato. Nesse momento ele se estabelece para além do bem e do mal. Mas, depois, quando do desdobramento da culpa, ante o anacronismo de uma responsabilidade, vem à tona a culpa e ele se mostra a quem do bem e do mal e volta a respeitar os marcos imortais da realidade (NIETZSCHE, 2006, p. 44) (VASSOLER, 2018).

Nessa linha, Platão, no conto do anel de Giges, também deixa transparecer as consequências que a ausência de empatia pode potencializar devido à ausência de patus conjunto - compaixão diante do outro.

No Conto do anel de Giges Platão narra o episódio em que Giges, munido de sua vontade niilista ${ }^{4}$, enxerga no dom da invisibilidade perante seus pares a possibilidade de

\footnotetext{
${ }^{4}$ Ao contrário do sentido empregado por Friedrich Nietzsche (2006, p. 76), o termo niilismo para sentido clássico significa a negação de princípios e valores tradicionalmente consagrados, sejam eles religiosos, morais, políticos ou sociais.
} 
atender seus desejos mais levianos levando-os às últimas consequências objetivando alcançar seus objetivos (PLATÃO, 2006, p. 50-55) exatamente por não estar submetido aos freios sociais do olhar do outro.

Assim, infere-se que com o distanciamento do outro dificulta-se a existência do sentimento de culpa porque o algoz desconhece a totalidade de sua responsabilidade - de sua culpa - perante o processo como um todo justamente porque esse processo fora fragmentado ceifando dele a noção do todo.

A título de exemplo, apegando-se a burocracia institucional, o nazismo levou-se às últimas consequências a ideia da maximização da dor alheia e desenvolveu um mecanismo impessoal que potencializou uma espécie de mecanismo de industrialização da morte.

À vista disso, na obra “As benevolentes”, tal mecanismo já denunciado por Dostoiévski em sua obra de ficção, fora evidenciado no mundo real e relatado por Jonathan Littell (2007, p 150).

Littell descreveu os horrores e o distanciamento do ser humano com o outro que fora empregado pelo nazismo para fragmentar o processo de industrialização da morte que culminaria com o resultado morte de milhares de pessoas.

O Littell, com rigor de detalhes, assim descreve:

\begin{abstract}
Em muitos casos, eu chegava a dizê-lo de mim para mim, aquilo que tomara por sadismo gratuito, a brutalidade inaudita com que certos homens tratavam os condenados antes de os executarem, mais não era do que uma consequência da piedade monstruosa que experimentavam e que, incapaz de se exprimir de outro modo, se transformava em raiva, mas uma raiva impotente, sem objecto, e que tinha quase inevitavelmente portanto de se virar contra os que eram a sua causa primeira. Se os massacres terríveis do Leste provam alguma coisa, é de facto, paradoxalmente, a medonha, a inalterável solidariedade da humanidade. Por mais brutalizados e mais habituados que estivessem a fazê-lo, nenhum dos nossos homens podia matar uma mulher judia sem pensar na sua mulher, na sua irmã ou na sua mãe, matar uma criança judia sem ver os seus próprios filhos à sua frente no fundo da vala. As suas reacções, a sua violência, o seu alcoolismo, as depressões nervosas, os suicídios, a minha própria tristeza, tudo isso demonstrava que o outro existe, existe enquanto outro, enquanto humano, e que nenhuma vontade, nenhuma ideologia, nenhuma quantidade de estupidez e de álcool pode romper esse laço, ténue mas indestrutível. Isto é um facto, e não uma opinião (LITTELL, 2007, p 150).
\end{abstract}

Como se percebe, mesmo sem o aparato tecnológico que existe hodiernamente, já fora possível, conforme relatado, viabilizar esse mecanismo imparcial de industrialização da morte.

Ademais, conforme a literatura citada, se verifica que na atualidade, época marcada pela concentração de informação por entes públicos e privados, possibilitou enumeras 
facilidades para a vida em sociedade, mas, por outro lado, de forma nunca antes vista, vislumbra-se a possibilidade de se existir um modelo de industrialização da morte ou de opressão ainda mais sofisticado do que aquele que fora empregado pelo nazismo.

O avanço tecnológico possibilitou diversos avanços, mas há cuidados que precisão sr tomados, pois na atualidade já se faz possível um monitoramento dos citadinos quase que onipresente que possibilita uma concentração de poder na mão de poucos humanos. Estes, por sua vez, alargaram seu poder e letalidade que pode ser direcionado a qualquer possível inimigo de ocasião por meio de instrumentos militares que viabilizam um ataque asséptico, implacável e fulminante com um apertar de botão

\section{CONCLUSÃO}

O aprimoramento das tecnologias pode vir trazer infindáveis benefícios para a vida em sociedade, mas fomentá-la de modo açodado pode vir a contribuir para o fortalecimento de um modelo dominante de pensamento ou para o enfraquecimento daquele modelo de pensamento tido por ruim pela força dominante de ocasião.

Assim, se por um lado vislumbra-se uma forma de unificar ou mitigar uma força de pensamento com o argumento falacioso de supostas verdades universais aplicáveis para todos e em qualquer lugar, tal modelo tende a tirania, pois, em caso de um uso desvirtuado da tecnologia, a "fiscalia" demasiada se torna uma potencial feramente de opressão e de medo para legitimar aquilo que se pretende por legitimo pela força dominante de ocasião, seja por uso da força física (bélica) ou doutrinação (apego ideológico).

Por todo o exposto, como já apontado, não se pode classificar a tecnologia como algo ruim ou algo bom, pois está, por si só, não possui um potencial exclusivamente destrutivo, pelo menos no estado atual da técnica, pois até o momento é o ser humanos que dá a ela a finalidade que este deseja.

Com efeito, mais do que nunca, a responsabilidade ética e moral de seus responsais ganha ainda maior relevância. Além do mais, deve ficar muito claro os fins que se está dado para o empregado dessa ou daquela tecnologia para que a sociedade e as autoridades públicas possam legalmente exercer controle sobre o emprego da tecnologia mais diversos campos da sociedade. 
Destarte, a sociedade e as autoridades responsáveis devem acompanhar e monitorar constantemente os rumos que estão sendo dado para esse ou para aquele modelo tecnológico para que de tal forma possa participar do processo de construção dessas ferramentas e ajudar com maximização dos riscos de tomadas de decisões equivocas por parte de seus responsáveis.

Assim, o modelo cooperativista demonstra-se competente para auxiliar no processo de elaboração, aprimoramento e calibragem das decisões que são realizadas por seus operadores.

Portanto, a discussão sobre os rumos éticos que estão sendo adotados deve, mais do que nunca, serem discutidos constantemente visando a ajustabilidade das condutas adotadas pelos entes privados, públicos e pelos demais membras do corpo social envolvido. 


\section{REFERÊNCIAS}

ALVES, Marco Antonio Sousa; NOBRE, Marcio Rimet. A Sociedade da Informação em Questão, o direito, o poder e o sujeito na contemporaneidade. Belo Horizonte: Editora D’Plácido, Belo Horizonte/MG, 2020.

BELL, Daniel. O Advento da Sociedade Pós-Industrial. São Paulo: Cultrix, 1974.

BIONI, Bruno Ricardo. Proteção de dados pessoais: a função e os limites do consentimento. Rio de Janeiro: Forense, 2019.

BRRETO JUNIOR, Irineu Francisco; VENTURINI JUNIOR. Gustavo. Fake news em imagens: um esforço de compreensão da estratégia comunicacional exitosa na eleição presidencial brasileira de 2018, REVISTA DEBATES, Porto Alegre, v. 14, n. 1, p. 04-35, jan.-abril. 2020.

CASTELLS, Manuel. A galáxia da Internet: reflexões sobre a Internet, os negócios e a sociedade. Trad. Maria Luiza X. de A. Borges. Rio de Janeiro: Jorge Zahar, 2003.

CASTELLS, Manuel. A Sociedade em Rede. São Paulo, Paz\&Terra, 2016.

CHAUÍ, Marilena. O que é ideologia. São Paulo: Brasiliense, 1984.

COSTA, Cristina; TORRES, Ricardo. To be or not to be, the importance of Digital Identity in the networked society. Educação, Formação \& Tecnologias. 2011.

СТАТОВСКИЙ, Дмитрий Александрович; СТАТОВСКАЯ, Елена Юрьевна. Блокчейн и криптовалюты в системе государственного управления. Финансы, n. 12, 2017.

DONEDA, Danilo. Da privacidade à proteção de dados pessoas. 2. ed. Revista dos Tribunais. 2019.

DOSTOIEVSKI, Fiodor Mikhailovitch. Crime e Castigo. Tradução: Paulo Bezerra. 6. ed. São Paulo: Editora 34, 2009.

DOSTOIEVSKI, Fiodor Mikhailovitch. Os Irmãos Karamázov. Tradução: Paulo Bezerra. 3. ed. São Paulo: Editora 34, 2012.

GIBSON, William. Neuromancer. New York: Electronic edition, 2003.

HARARI, Yuval Noah. 21 lições para o século 21. São Paulo: Companhia das Letras, 2018.

KELLNER, Douglas. Como mapear o presente a partir do futuro: de Baudrillard ao cyberpunk. A cultura da mídia. Bauru: EDUSC, 2001.

KLIMKE, Romy. Menschenrecht auf einen Internetzugang?. 2020. Disponível em: https://verfassungsblog.de/menschenrecht-auf-einen-internetzugang/. Acesso: 26 jun. 2020. 
LÉVY, Pierre. As tecnologias da inteligência: o futuro do pensamento na era da informática. São Paulo: Editora 34, 1993.

LÉVY, Pierre. Cibercultura. Rio de Janeiro: Editora 34, 1999.

LITTELL, Jonathan. As benevolentes. Tradução: Miguel Serras Pereira. Alfragide: Dom Quixote, 2007.

MONTEIRO, Silvana Drumond; PICKLER, Maria Elisa Valentim. O ciberespaço: o termo, a definição e o conceito. DataGramaZero-Revista de Ciência da Informação, v. 8, n. 3, p. 121, 2007.

NIETZSCHE, Friedrich. Crepúsculo dos ídolos. Tradução: Paulo César de Souza. São Paulo: Companhia das Letras, 2006.

OLIVEIRA, Beatriz Martins de; WALDMAN, Ricardo Libel. Conceitos de informação e sociedade da informação e sua importância. Revista Meritum, Belo Horizonte, vol. 15, n. 4, p. 246-259, 2020. DOI: https://doi.org/10.46560/meritum.v15i4.7965.

PALERMO, Francesco. Is there a space for federalism in times of emergency?. 2020. Disponível em: https://verfassungsblog.de/is-there-a-space-for-federalism-in-times-ofemergency/. Acesso em: 27 out. 2020.

PLATÃO. A República. São Paulo: Martins Fontes, 2006.

REPÚBLICA FEDERATIVA DO BRASIL. Tribunal de Contas da União. TC 031.044/20190. 2020. https://autenticidade-

documento.apps.tcu.gov.br/documento?numeroDocumento=64747203. Acesso em: $01 \mathrm{abr}$. 2021.

SCHAUB, Mark. The Era of Digital Trust. Blockchain for Lawyers. 2018. Disponível em: https://www.legaler.com/wp-content/uploads/2018/12/Blockchain-for-Lawyers-

eBook.pdf?utm_medium=email\&utm_campaign=eBook\%20Delivery\&utm_content $=$ eBook\% 20Delivery $+\& u t m \_s o u r c e=C M \& u t m \_t e r m=C l i c k \% 20$ Here $\% 20$ to $\% 20$ Download $\% 20 \mathrm{eBook}$. Acesso em: 22 set. 2019.

TANENBAUM, Andrew S. Redes de Computadores. 4. ed. Editora Campus. 2003.

VASSOLER, Flávio Ricardo. Dostoiévski: crimes sem castigo | Flávio Ricardo Vassoler. 2018. Disponível em:

https://www.youtube.com/watch?v=VtJDdf60fJE\&ab_channel=Caf\%C3\%A9Filos\%C3\%B3f icoCPFL. Acesso em: 12 mar. 2021.

VIEIRA, Euripedes Falcão. A sociedade cibernética. Cadernos Ebape. BR, v. 4, n. 2, p. 0110, 2006.

Wong, K. L. X.; Dobson, A. S. We're just data: Exploring China's social credit system in relation to digital platform ratings cultures in Westernised democracies. Global Media and China, 2019. 